\title{
The Effect of Perceived Discrimination on Gender Role Conflict Among Men Engaged in A-typical Occupations: The Moderating Role of Work Autonomy
}

\author{
Olubukola Abimbola Oke \\ Department of Behavioural Studies, College of Management \& Social Sciences, Redeemer's University, Oshogbo, Nigeria
}

Email address:

okeo@run.edu.ng

To cite this article:

Olubukola Abimbola Oke. The Effect of Perceived Discrimination on Gender Role Conflict Among Men Engaged in A-typical Occupations: The Moderating Role of Work Autonomy. Social Sciences. Vol. 8, No. 3, 2019, pp. 117-124. doi: 10.11648/j.ss.20190803.17

Received: April 2, 2019; Accepted: May 16, 2019; Published: June 26, 2019

\begin{abstract}
Empirical research suggests that gendered job-segregation have effects on men in the workplace consequent upon bias evaluations stemming from social norms regarding acceptable gender roles. These biases are capable of inducing workplace stressors that may affect the psychological well being of men engaged in female-dominated occupations. This study investigates the moderating role of work autonomy in the relationship between perceived gender discrimination and gender role conflict for men in atypical occupations. A cross-sectional survey method was used to collect data from a sample of 150 men in the occupations of nursing, librarian, and primary school teaching, and a hierarchical regression test analyzed hypotheses. Regression analysis demonstrated that perceived discrimination and work autonomy were significant predictors of gender role conflict $(\beta=.60, \mathrm{p}<.001)$, and $\beta=-.62, \mathrm{p}<.001$, respectively). A moderated regression analysis was also conducted to test the assumption that job autonomy moderates the relationship between perceiving a discriminatory work environment and workers' gender role conflict. The analysis indicated that $79 \%$ of the variation in the dependent variable could be explained by the main effects and the interaction effects, $\mathrm{F}(4,145)=140.58, \mathrm{p}<.05)$. This interaction effect, although significant, accounted for a minimal incremental effect above and beyond the direct effects of perceived gender discrimination and work autonomy $(\Delta \mathrm{R} 2=.008, \mathrm{~F}(1,145)=5.48, \mathrm{p}<.05)$. Research implications and suggestions for future research are discussed.
\end{abstract}

Keywords: Gender, Stereotypes, Masculinity, Autonomy, Discrimination

\section{Introduction}

Occupational gender segregation is a persistent and objective reality in the contemporary world of work where the labour market continues to be segregated along the lines of gender in several occupations. Society places gender expectations on both men and women that become standard in the workplace and the home. This sex-based occupational segregation is embedded in socio-cultural norms that often determine the appropriateness of an occupation for a man or a woman [1]. Thus, typically female occupations are known to involve principally non-manual tasks, such as service professions or providing care for people, with lower income and few career prospects, while typically male occupations are mainly characterised by manual tasks that are, for instance, physically demanding and often provide higher pay, more stability, and higher prestige [2].

A man may be employed in a gender-typical occupation, which is an occupational group of whom the majority of employees are made up by men, or a gender-atypical occupation, where men are a numerical minority. Group membership to the category 'male' therefore generates a range of expected behaviours, within oneself and in others, including a variety of suited occupations that are associated with membership to this category [3]. When one's profession is not within the scope of typically related occupations for the group 'male,' which is the case for men working in genderatypical occupations, an individual may suffer negative, limiting stereotyping from clients, female colleagues, or the general public [4]. Due to this categorization, various psychological processes could occur that are likely to influence job performance and mental well being [5-7]. 
The argument is that for men engaged in these jobs; a possible gender role conflict may arise due to discrepancies between culturally defined sex roles versus professional role roles that differ in quality or character. A gender-atypical occupation may be threatening to perceived manhood [8]. In many contexts, masculinity is displayed by qualities such as physical strength, protector, autonomy, leadership, achievement, taking initiatives, assertive, suppression of emotions, competitiveness, aggression, dominance over women, heterosexual prowess, toughness [9-10]. A "typical" woman is expected to be tender, nurturing, submissive, affectionate, patient, passive, responsive, etc. [6, 11-12]. These traits and attributes are also often found in job descriptions.

Research has found that male nurses and librarians are stereotyped as social deviants, weak, skirt-chasers, effeminate, possibly gay or not smart enough to succeed in higher status specialties-for example, as a surgeon [7, 13-14]. Teaching, particularly of young children, has been associated more with women's mothering traits and relational or soft skills, over technical skills or knowledge [15-16]. Men employed in this field have been viewed suspiciously because their presence is seen as violating traditional gender norms and even branded as sexual predators and a threat [1719]. For example, perceiving a more significant conflict between their gender and their job has been linked to higher rates of depression and anxiety, as well as lower job satisfaction and commitment, among male nurses, early childhood educators, and flight attendants [20-22].

In contemporary society, modernization and globalization have brought to the fore changing expectations and nontraditional messages about desired masculine and feminine behaviour, all which fosters an environment that is contributing to gender role conflict within men [23-24]. Adherence to rigid traditional gender roles and the societal pressure to conform to contemporary trends can lead to high levels of internal conflict and conflict with others, especially for men engaged in occupations dominated by women. As defined [25], men's gender role conflict is a psychological state in which restrictive definitions of masculinity limit have a negative consequence on the person or others. These restrictions are proscribed by hegemonic masculinity ideology internalized during the socialization process and reinforced by parents, teachers, peers, and the media. Research relates men's gender role conflict to a myriad of behavioral problems, including sexism [23], violence, homophobia, depression [26], substance abuse [27], and relationship issues.

With this background, this current study explores workrelated variables that have been identified in the literature as stressors and resource contributing to gender role conflict among men engaged in atypical occupations. The objectives of the study are to (1) examine the predicting influence of perceived gender discrimination, and work autonomy on gender role conflict among men, and (2) examine the moderating role of work autonomy between perceived gender discrimination and gender role conflict.

\subsection{Gender Role Conflict and Perceived Gender Discrimination}

Perceived gender discrimination is an individual's perception that he or she is treated differently or unfairly because of his or her group membership. Furthermore, when individuals feel they are mistreated because of their group membership, they often feel alienated and angry, which can result in negative work-related behaviours. Empirical evidence shows that perceiving discrimination is a stressor which reduces physical and psychological health; reduce self-esteem, decreases job satisfaction, and increases job tension [28-29]. Research with men has shown that they do experience many of the same negative personal and occupational pressures associated with being a token that women experience in male-dominated occupations [30]. For example, a study of a group of male nurses concluded that male symbols experienced both formal (e.g., restriction from delivery room specialties) and informal (e.g., exclusion from conversations between female colleagues) discrimination [31]. Men employed in non-traditional jobs also face the challenge of achieving an appropriate balance of masculinity. If they are 'too masculine' then their sexual intentions may be called into question, or they may be accused of being exploitative. If their masculinity is deemed to be 'too passive' then the common assumption is that they are probably gay [32-33]. Another author [19] argues that specific feminised care jobs are commonly deemed to entail specific skill and emotions which women are better at than men because women are the primary carers in gendersegregated family roles. Hence men's suitability and motives may often be in question in the minds of employers, colleague, and clients for many jobs connected with young people and nursing, especially following the recent increase in cases of child abuse and rape of minors [34]. Therefore the following hypothesis is made:

Hypothesis 1: Perceived gender discrimination will be positively related to gender role conflict.

\subsection{GRC and Work Autonomy}

In the workplace, autonomy, also referred to as job control is measured in terms of how much freedom an individual has to make decisions, either for the company or on how a task becomes accomplished, how much creativity and innovation an employee can express, and how much external influence affects an employee's work [35-36]. Work autonomy, which is a job resource, is an essential predictor of proactive outcomes for employees [37-38]. Autonomy expressed through authority, independence, and leadership is one of the traditional masculine traits and can be linked to the patriarchal rules of society. In a patriarchal culture, men have higher status and power than women; male dominance (power \& control) is the norm in the public and private sphere, especially in decision making. It is argued that when a man finds himself as a minority in the workplace, with perceived workplace gender discrimination, and yet has to defer to others (possibly women superiors), it could engender 
role conflict. However, recognizing a discriminatory work environment might inhibit employees from using work autonomy, which also might decrease its positive effects. Employees who possess a high level of work autonomy, given the flexibility they have in terms of how their work tasks and processes are developed and organized, can use this power to able to avoid situations which are perceived as discriminatory and interfere with their gender role selfconcept. This reasoning leads to the prediction that:

Hypothesis 2a: Work autonomy will show a statistically significant negative relationship to gender role conflict.

Hypothesis 2b: Work autonomy will moderate the relationship between perceived gender discrimination and gender role conflict such that the more work autonomy an individual has, the less perceiving a discriminatory work environment will induce gender role conflict.

\section{Materials and Methods}

\subsection{Participants and Procedure}

This was a cross-sectional study carried out in Lagos state, Nigeria. The research sample was a convenience sample of 150 men employed in empirically identified femaledominated occupations of nursing $(\mathrm{n}=50)$, primary school teachers $(n=50)$, and librarians $(n=50)$. Participants were contacted through their usual places of work, the purpose of the study was explained to them, and willingness to complete the research instrument was taken as informed consent. Data were collected through a self-reported questionnaire, and participants were informed about the anonymity and confidentiality of the survey.

Table 1. Sociodemographic characteristics of participants $(N=150)$.

\begin{tabular}{lllll}
\hline Variable & Mean & SD & Median & Range \\
\hline Age & 39.69 & 8.03 & 38 & $28-58$ \\
Job tenure & 7.91 & 5.00 & 6.15 & $1-25$ \\
Average weekly work hours & 47.79 & 15.00 & 42.50 & $30-75$ \\
\hline \multicolumn{5}{c}{} \\
\hline \multicolumn{5}{c}{$\mathbf{\%}$} \\
\hline Marital Status & $\mathbf{N}$ & & \\
Single & 49 & & 32.7 & \\
Married & 101 & 67.3 & \\
\hline
\end{tabular}

\subsection{Measures}

\subsubsection{Gender Role Conflict ( $\alpha=0.66)$}

A 16-item modified short form of the Gender Role Conflict Scale [39] was used to assess patterns of gender role conflict among the participants. It is one of the primary measures of men's reactions to the inconsistent gender role expectations they face. The GRCS-SF was chosen for this research to reduce the response burden and increase the likelihood of achieving a higher and more accurate response rate. It comprises of four subscales, each measured with four items: (1) Success, Power, and Competition, (2) Restrictive Emotionality, (3) Restrictive Affectionate Behaviour between Men and (4) Conflicts between Work \& Family Relations. Participants were instructed to rate the 16 items on a 6-point
Likert scale with responses ranging from (1) strongly disagree to (6) strongly agree. High scores imply higher levels of gender role conflict.

\subsubsection{Perceived Gender Discrimination $(\alpha=0.89)$}

This variable was measured by the aggregate score of a scale of ten items, representing ten types of workplace discrimination. The items were adapted from a scale [40] with 18 items measuring the extent to which employees perceive race-based and sex-based discrimination in the workplace. For this study, the nine items measuring genderbased discrimination was slightly modified to include two items about perceived gender discrimination from clients. Examples of items are: I have been treated unfairly by coworkers or colleagues because of my gender; I feel that others exclude me from their activities because of my gender; Clients have misunderstood my motives/intentions because of my gender. The ten items were rated on a 5-point Likert Scale ranging from 1 (Strongly disagree) to 5 (Strongly agree) where higher scores implied higher levels of perceived gender discrimination.

\subsubsection{Work Autonomy $(\alpha=0.78)$}

The Smith, Tisak, Hahn, and Schmieder's [41] revised version of the Worker Control Scale [42] was used. The scale had nine items, but I added the item to measure taking initiatives to make a total of 10 questions for this study, all measuring the amount of decision authority participants have over their work processes. Responses were scored on a fourpoint Likert scale ranging from 1 (Very little) to 5 (Very much) where higher scores indicated increased levels of work autonomy. An example of an item is, "Does your job require you to take the initiative?"

\section{Analysis}

Survey results were analysed using SPSS Version 20.0. Descriptive analyses included frequencies and percentages for categorical variables and means and standard deviations (SDs) for continuous variables. The dependent (gender role conflict) and independent variables (gender role ideology, perceived gender discrimination, and work autonomy) were all treated as continuous. A Pearson correlation analysis was first carried out to explore the association between variables included in the study, followed by a stepwise, hierarchical regression analysis, which was used to determine the influence of the independent variables on the prediction of gender role conflict (hypotheses 1 and 2a). To test for potential interaction effects, a multiplicative interaction term was included for hypothesis 2b. Following the recommendation of Hofmann and Gavin [43], group means centering was used for all individual-level predictors. The 0.05 level of probability was used to reject or fail to reject the null hypotheses.

\section{Results}

Before conducting the hierarchical multiple regression, the 
relevant assumptions of this statistical analysis were tested. Firstly, a sample size of 150 was deemed adequate, given three independent variables to be included in the analysis [44]. The assumption of singularity was also met as the independent variables (job tenure, perceived gender discrimination, and work autonomy) were not a combination of other independent variables. Table 2 reflects the means, standard deviations, as well as correlation coefficients among independent, dependent, and control variable. An examination of correlations (see Table 2) revealed that no independent variables were highly correlated, except for perceived gender discrimination and work autonomy $(\mathrm{r}=.69$, $\mathrm{p}<.001)$. All other correlations were moderate, ranging between $\mathrm{r}=.48, \mathrm{p}<.001$ and $\mathrm{r}=.52, \mathrm{p}<.001$. All predictor variables were statistically correlated with gender role conflict, which indicates that the data was suitably correlated with the dependent variable for examination through multiple linear regressions to be reliably undertaken [45]. The correlations between the predictor variables and the dependent variable were all moderately to very strong, ranging from $r=.52, p<.001$ to $r=.85, p<.001$.

Because some of the correlations were strongly correlated, other indices of multicollinearity were further examined and found to be acceptable: (1) tolerance values were higher than 0.2 , and (2) VIF values were below 10 [46-47]. As shown in Table 3, this is not the case for any of the independent variables it can be then concluded that the assumptions of multicollinearity were not violated in this dataset.

Table 2. Means, standard deviations, and correlations among study variables.

\begin{tabular}{lllllll}
\hline Variables & Mean & SD & $\mathbf{1}$ & $\mathbf{2}$ & $\mathbf{3}$ & $\mathbf{4}$ \\
\hline JT & 7.91 & 6.15 & ---- & & & \\
PGD & 27.93 & 8.08 & $-.52^{* *}$ & --- & & \\
WA & 24.95 & 5.22 & $.48^{* *}$ & $-.69^{* *}$ & --- & \\
GRC & 52.98 & 7.61 & $-.57^{* *}$ & $.74^{* *}$ & $-.85^{* *}$ & --- \\
\hline
\end{tabular}

Note: $\mathrm{N}=150, \mathrm{JT}=\mathrm{Job}$ tenure, $\mathrm{PGD}=$ Perceived gender discrimination, WA

$=$ Work autonomy, $\mathrm{GRC}=$ Gender role conflict, ${ }^{* *} \mathrm{p}<0.01$.

As stated before, higher scores mean higher levels of gender role conflict. For this reason, from the correlation analysis, the relationship between experiencing a discriminatory work environment and gender role conflict is positive and also significant $(\mathrm{r}=.74, \mathrm{p}<.001)$. Moreover, perceiving a discriminatory work environment is significantly inversely related with work autonomy $(r=.69, \mathrm{p}$ $<.001$ ), thus higher levels of gender role conflict are associated with higher levels of perceived discrimination and lower rates of job autonomy.

To test the hypotheses, a stepwise hierarchical multiple regression was conducted with gender role conflict as the dependent variable (Table 3). Perceived gender discrimination was entered at step 1 while controlling for job tenure and the total variance explained by the model was $59 \%(F(2,147)=$ 108.75; $\mathrm{p}<.001)$. Results show that perceiving a discriminatory work environment is positively and significantly enhanced gender role conflict $(\beta=.60, \mathrm{p}<.001)$. After entry of work autonomy in step 2, the results indicated that the model accounted for $78 \%$ of the variance in gender role conflict. Job autonomy was significantly and negatively related to gender role conflict $(\beta=-.62, p<.001)$; therefore, people with higher rates of job autonomy will report less gender role conflict. Importantly, the effect of perceiving a discriminatory work environment on gender role conflict is reduced with the introduction of job autonomy $(\beta=-.22$, $p$ $<.001)$. This model further explained an additional $19 \%$ of the variance above and beyond the variance accounted for by perceived gender discrimination, $F(1,146)=131.64, p<.001$. Finally, in the third step of the regression analysis, the perceived gender discrimination $\mathrm{x}$ work autonomy interaction was entered to assess the moderating effect of work autonomy on the perceived gender discrimination-gender role conflict relationship. The analysis indicated that $79 \%$ of the variation in the dependent variable could be explained by the main effects and the interaction effects, $F(4,145)=140.58, \mathrm{p}<.05)$. This interaction effect, although significant, accounted for a minimal incremental effect above and beyond the direct effects of perceived gender discrimination and work autonomy $\left(\Delta \mathrm{R}^{2}\right.$ $=.008, \mathrm{~F}(1,145)=5.48, \mathrm{p}<.05)$. Therefore, the relationship between perceived gender discrimination and gender role conflict was moderated by work autonomy $(\beta=-.09, \mathrm{p}<.05)$.

Table 3. Hierarchical Regression on Gender Role Conflict.

\begin{tabular}{|c|c|c|c|c|c|c|c|}
\hline Variables & & $\boldsymbol{R}$ & $R^{2}$ & $\Delta R^{2}$ & $\boldsymbol{\beta}$ & $\begin{array}{l}\text { Tolerance } \\
\text { Scores }\end{array}$ & VIF Scores \\
\hline Step 1 & & .77 & .59 & & & & \\
\hline Job Tenure & & & & & $-.25 * * *$ & .721 & 1.388 \\
\hline Perceived Discrimination & & & & & $.60 * * *$ & .721 & 1.388 \\
\hline Step 2 & & .88 & .78 & $.19 * * *$ & & & \\
\hline Job Tenure & & & & & $-.15 * *$ & .695 & 1.440 \\
\hline Perceived Discrimination & & & & & $.22 * * *$ & .464 & 2.155 \\
\hline Work Autonomy & & & & & $-.62 * * *$ & .492 & 2.031 \\
\hline Step 3 & & .89 & .79 & $.008 *$ & & & \\
\hline Job Tenure & & & & & $-.13 * *$ & .669 & 1.494 \\
\hline Perceived Discrimination & & & & & $.25 * * *$ & .427 & 2.047 \\
\hline Work Autonomy & & & & & $-.63 * * *$ & .488 & 2.047 \\
\hline $\begin{array}{l}\text { Perceived Discrimination } \\
\text { Autonomy }\end{array}$ & X Work & & & & $-.09 *$ & .834 & 1.199 \\
\hline
\end{tabular}

Notes: $\mathrm{N}=150 ;{ }^{*} \mathrm{p}<0.05 ; * * \mathrm{p}<0.01 ; * * * \mathrm{p}<0.001$. 


\section{Discussion}

The present study extends findings on predictors of gender role conflict among men engaged in atypical occupations of nursing, primary school teacher, and librarian. The objectives of the current study were (1) to examine the relation and contribution of, perceived gender discrimination and work autonomy to gender role conflict while controlling for job tenure; and (2) to determine whether work autonomy moderated the relation of perceived gender discrimination to gender role conflict. Results from the correlation analysis showed that both independent variables were all significantly related to the dependent variable, with work autonomy having the most solid relationship to gender role conflict.

Hypothesis 1 predicted that perceived gender discrimination would be positively related to gender role conflict. This hypothesis was fully supported as results of the regression analysis indicated that as the level of perceived gender discrimination in the sample increased, the level of gender role conflict also increased. This result is consistent with the body of research showing that exposure to discrimination deteriorates mental and physical health [48-49]. In gender-segregated occupations, women in male-dominated professions tend to report more anxiety or mood disorders while male employees in female-dominated occupations report more ill-health symptoms [50-51]. Also, results from another study [52] suggest that males and females employed in occupations where their gender was dominant had better mental health than those in genderneutral professions. For many adults, anticipating discrimination as a result of one's social identity results in a state of heightened vigilance and changes in behaviour, which in itself can trigger stress responses - taking care about what they say or do and how they say or do it, as well as to avoid certain situations, to cope with such discrimination [53-54]. This heightened vigilance can lead to negative emotions and depleted cognitive resources [5557].

According to study [58-59], in female-dominated occupations, tendencies toward the femininisation of the work and client relationships put some strain on gender identity for men and to overcome stereotype threat, they may have to exert self-control, often having to work harder to maintain performance in the face of such threat. Another area of concern is that stereotype threat arising from gender discrimination may interfere with an individual's ability to integrate personal identities (being a man) with professional identities (e.g., being a nurse) which could likely result in stress [60]. This disengagement has been shown to negatively impact task performance, self-esteem, and motivation, such that individuals will give up more quickly on a stereotyperelevant task while under threat because of the anticipated feedback that follows. Faced with potential challenges to their "masculinity," men working in female-dominated occupations, as a coping mechanism, tend to dissociate themselves from tasks and or abilities connected with their jobs that are considered to be "feminine" and embrace the more "masculine" dimensions [61-62].

It was further predicted that work autonomy would show a statistically significant negative relationship to gender role conflict, and this hypothesis was supported. The results showed that work autonomy negatively predicted gender role conflict such that as the level of work autonomy increased, the levels of gender role conflict inversely reduced. According to the second part of Hypothesis 2 results also showed that work autonomy marginally moderates the relationships between perceiving a discriminatory work environment and workers' gender role conflict. In line with previous studies, the results confirm that job autonomy is a vital resource connected with psychological well-being [63]. This could mean that people who have freedom in their jobs have more possibilities to control their work environment and the ability to withstand social pressures, which might make them feel less affected at the psychological level by a discriminatory work environment since they can avoid it, thereby improving their mental well being [64-66].

Strengths and Limitations

Some limitations have to be discussed. First, the generalization of the findings is restricted since the study employed a sample of employees of the conveniently selected occupations, organizations, and the small sample size. Second, this study cannot confirm causality among the variables studied because the data came from a crosssectional survey. Thus, replication would be warranted in different work settings and among a larger sample to enhance generalization, while taking into gender distribution in the work settings.

Furthermore, by using subjectively reported information as a predictor and as outcome variables, influences of personal factors of the study, participants cannot be excluded. While the survey used in this study covers a variety of aspects of individual work autonomy including, there is also a need to assess worker's autonomy at the organizational level, since the effect of work autonomy may be contingent on organizational factors. Future investigation on organizational contexts in which work autonomy is more effective should also be investigated, and the inclusion of more predictor and moderator variables is encouraged.

\section{Conclusion}

At a general level, this study emphasizes the importance of a job resource (work autonomy) in counteracting the adverse effects of perceiving a discriminatory work environment (stressor) for men working in atypical occupations, thereby improving psychological their well being. As more men make nontraditional career choices, it becomes essential to have more studies investigating the impact of their career choices on themselves, changes in their roles within the family, and society. It will be interesting to also look at the importance of gender role socialisation within their career 
choices. People need to see a friendly and supporting environment, but also they need to recognize that in their organization there is no room for discrimination [67]. In terms of practical implications, job crafting might be a solution to adjust some aspects of the job to the male worker's needs, providing more gender identity support to reduce stress and increasing resources [68].

\section{References}

[1] Eagly, A. H., and Wood, W. nature-nurture debates 25 years of challenges in understanding the psychology of gender. 2013; Perspect. Psychol. Sci. 8, 340-357. https://doi.org/10.1177/1745691613484767.

[2] Levanon, A., \& Grusky, D. The persistence of extreme gender segregation in the twenty-first century American. 2016; American Journal of Sociology, 122 (2), 573-619.

[3] Fiske, S. T., Gilbert, D. T., \& Lindzey, G. Handbook of social psychology, 2010; (Vol. 2). John Wiley \& Sons: New York.

[4] Kanter, R. M. Men, and women of the corporation (2nd ed.). 1993; New York, NY: Basic Books.

[5] Vandello, J. A., \& Bosson, J. K. Hard won and easily lost: A review and synthesis of theory and research on precarious manhood. 2013; Psychology of Men \& Masculinity, 14 (2), 101. https://doi.org/10.1037/a0029826.

[6] Korek, S., Sobiraj, S., Weseler, D., Rigotti, T., \& Mohr, G. The gender role self- concept of men in female-dominated occupations: does it depend on how they see their jobs? 2014; Journal of Applied Social Psychology, 44 (4), 241-254. https://doi.org/10.1111/jasp.12235.

[7] Clow, K., Ricciardelli, R., \& Bartfay, W. Are you man enough to be a nurse? The impact of ambivalent sexism and role congruity on perceptions of men and women in nursing advertisements. 2015; Sex Roles 72 (7-8), 363-376. https://doi.org/10.1007/s11199-014-0418-0.

[8] Vandello, J. A., Bosson, J. K., Cohen, D., Burnaford, R., \& Weaver, J. Precarious manhood. 2008; Journal of Personality and Social Psychology, 95: 1325-1339. https://doi.org/10.1037/a0012453.

[9] Way N., Cressen J., \& Bodian S. "It might be nice to be a girl... Then you wouldn't have to be emotionless": Boys' resistance to norms of masculinity during adolescence. 2014; Psychol Men Masc.; 15: 241-252.

[10] Kågesten A., Gibbs S., Blum R. W. Understanding factors that shape gender attitudes in early adolescence globally: A Mixed-Methods systematic review. PLoS One. 2016; 11: e0157805.

[11] Koenig, A. M., \& Eagly, A. H. Evidence for the social role theory of stereotype content: observations of groups' roles shape stereotypes. 2014; J. Pers. Soc. Psychol. 107, 371-392. https://doi.org/10.1037/a0037215.

[12] Schmader, T., \& Block, K. Engendering identity: Toward a clearer conceptualization of gender as a social identity. 2015; Sex Roles, https://doi.org/10.1007/s11199-015-0536-3.

[13] Piper, P. S., \& Collamer, B. E. Male librarians: Men in a feminized profession. 2001; The Journal of Academic
Librarianship, 27 (5), 406-411.

[14] Burton, D. A. \& Misener, T. A. Are you man enough to be a nurse? Challenging male nurse media portrayals and stereotypes. In C. O'Lynn \& R. Tranberger (Eds.) Men in Nursing: History, Challenges, and Opportunities; 2007 (pp 255-269). New York: Springer Publishing.

[15] Pinnegar, S., Dulude, C. L., Bigham, S. \& Dulude, C. Teaching as Highlighted by Mothering: A Narrative Inquiry. 2005; Studying Teacher Education, 1 (1): 55-67.

[16] Bolton, S \& Muzio, D. The paradoxical processes of feminization in the professions: the case of established, aspiring, and semi-professions. 2008; Work, Employment, and Society, 22: 281-299.

[17] Bakker, A. B., \& Bal, M. P. Weekly work engagement and performance: A study among starting teachers. 2010; Journal of Occupational and Organizational Psychology, 83 (1), 189 206.

[18] Lupton, B. Explaining men's entry into female-concentrated occupations: issues of masculinity and social class. 2006; Gend. Work Organ. 13, 103-128. https://doi.org/10.1111/j.1468-0432.2006.00299.x.

[19] Simpson, R. Men in Non-Traditional Occupations: Career Entry, Career Orientation, and Experience of Role Strain. 2005; Gender, Work, and Organization; 12 (4): 363-380.

[20] Young, J. L., \& James, E. H. Token majority: the work attitudes of male flight attendants. 2010; Sex Roles 45, 299 319. https://doi.org/10.1023/A: 1014305530335.

[21] Wolfram, H. J., Mohr, G., \& Borchert, J. Gender role selfconcept, gender role conflict, and well-being in male primary school teachers. 2009; Sex Roles 60, 114-127. https://doi.org/10.1007/s11199-008-9493-4.

[22] Wallen, A. S., Mor, S., \& Devine, B. A. It's about respect: gender professional identity integration affects male nurses' job attitudes. 2014; Psychol. Men Masc. 15, 305-312. https://doi.org/10.1037/a0033714.

[23] O’Neil, J. M. Men's gender role conflict: Psychological costs, consequences, and an agenda for change. 2015; Washington, D. C.: American Psychological Association.

[24] Wong, Y. J., Ho, M. R., Wang, S. Y., \& Miller, I. S. Metaanalyses of the relationship between conformity to masculine norms and mental health-related outcomes. 2017; Journal of Counseling Psychology, 64, 80-93. http://doi.org/10.1037/cou0000176.

[25] O'Neil, J. M. (2008). Summarizing 25 years of research on men's gender role conflict using the gender role conflict scale. The Counseling Psychologist, 36, 358-445.

[26] Fujimoto, T., Shinohara, S., \& Oohira, T. 2014. Work-Family Conflict and Depression for Employed Husbands and Wives in Japan: Moderating Roles of Self and Spousal Role Involvement, in (ed.) Family Relationships and Familial Responses to Health Issues (Contemporary Perspectives in Family Research, Volume 8A) Emerald Group Publishing Limited, pp. 135-162.

[27] Beehr, T. A., Bowling, N. A., \& Bennett, M. M. Occupational stress and failures of social support: When helping hurts. 2010; Journal of Occupational Health Psychology, 15, 45-59. https://doi.org/10.1037/a0018234. 
[28] Di Marco, D., López-Cabrera, R., Arenas, A., Giorgi, G., Arcangeli, G., \& Mucci, N. Approaching the discriminatory work environment as a stressor: the protective role of job satisfaction on health. 2016; Front. Psychol. 7: 1313. https://doi.org/10.3389/fpsyg.2016.01313.

[29] Jones, K. P., Arenas, D. F., Nittrouer, C. L., Alonso, N. M., \& Lindsey, A. P. Subtle discrimination in the workplace: a vicious cycle. 2017; Ind. Organ. Psychol. 10, 51-76. https://doi.org/10.1017/iop.2016.91.

[30] Booth, A. L. \& Leigh, A. Do Employers Discriminate by Gender? A Field Experiment in Female-Dominated Occupations”, 2010; CEPR Discussion Paper No. 7638, January.

[31] Rajacich D, Kane D, Wilson C, \& Cameron. If they do callyou nurse, it is always a 'male nurse': Experiences of men in the nursing profession. Nursing Forum. 2013; 48 (1): 71-80. https://doi.org/10.1111/nuf.12008.

[32] Cross, S. \& Bagihole, B. 'Girls' jobs for the boys? Men, masculinity, and non-traditional occupations'. 2002; Gender, Work and Organization, 9 (2), 204-26.

[33] Riach, P. \& Rich, J. “An Experimental Investigation of Sexual Discrimination in Hiring in the English Labour Market," 2006; BE Press Advances in Economic Analysis \& Policy, 6 (2): 1-22.

[34] Rolfe, H. Where are the men? Gender Segregation in the Childcare and Early Years. 2006; National Institute Economic Review; $\quad 195 \quad$ (1): $103-117$. https://doi.org/10.1177/0027950106064038.

[35] Parker, S. K. Beyond motivation: job and work design for development, health, ambidexterity, and more. 2014; Annu. Rev. Psychol. 65, 661-691. https://doi.org/10.1146/annurevpsych-010213-115208.

[36] Ohly, S., \& Fritz, C.Work characteristics, challenge appraisal, creativity, and proactive behavior: A multi-level study. 2009; Journal of Organizational Behavior, 31, 543-565. https://doi.org/10.1002/job.633.

[37] Gaille, D. Direct participation and the quality of work. 2013; Hum. Relat. 66, 453-473. https://doi.org/10.1177/0018726712473035.

[38] Kubicek, B., Paskvan, M., \& Bunner, J. (2017). "The bright and dark sides of job autonomy," in C. Korunka and. Kubicek (Eds.) Job Demands in a Changing World of Work, (Dordrecht: Springer International), 45-63.

[39] Wester, S. R., Vogel, D. L., O'Neil, J. M., \& Danforth, L. Development and Evaluation of the Gender Role Conflict Scale-Short Form (GRCS-SF). 2011; Psychology of Men \& Masculinity. ttps://doi.org/10.1037/a0025550.

[40] Jagusztyn, N. E. 2010. Perceived Workplace Discrimination as a Mediator of the Relationship between Work Environment and Employee Outcomes: Does Minority Status Matter? Graduate Theses and Dissertations. http://scholarcommons.usf.edu/etd/3657.

[41] Smith, C., Tisak, J., Hahn, S., \& Schmieder, R. The measurement of job control. 1997; Journal of Organizational Behavior, 18, 225-237.

[42] Ganster, D. C. Worker control, and well-being: A review of research in the workplace. In Sauter, S. L., Hurrell, J. J. \& Cooper, C. L. (Eds.) Job Control and Worker Health, 1989. Chichester, UK: Wiley.
[43] Hofmann, D. A., \& Gavin, M. B. Centering decisions in hierarchical linear models: Implications for research in organizations. 1998; Journal of Management, 24 (5), 623-641.

[44] Pallant, J. (2005). SPSS Survival Manual: A step by step guide to data analysis using SPSS for Windows (Version 12). Crows Nest, NSW: Allen \& Unwin.

[45] Tabachnick, B. G., \& Fidell, L. S. 2007. Using Multivariate Statistics, $\left(5^{\text {th }}\right.$ Edition $)$. Boston: Pearson Education, Inc.

[46] Tabachnick, B. G., \& Fidell, L. S. 2013. Using Multivariate Statistics, 6th ed. Boston: Pearson Education, Inc.

[47] Saunders, M., Lewis, P. \& Thornhill, A. 2016. Research methods for business students ( $7^{\text {th }}$ ed.). Harlow, UK: Pearson Education.

[48] Schmitt, M. T., Schmitt, M. T., Branscombe, N. R., \& Garcia, A., The consequences of perceived discrimination for psychological well-being: a meta-analytic review. 2014; Psychol. Bull. 140, 921-949. https://doi.org/10.1037/a0035754.

[49] Yang, T., \& Park, K., To what extent do sleep quality and duration mediate the effect of perceived discrimination on health? Evidence from Philadelphia. 2015; J. Urban Health 92, 1024-1037. https://doi.org/10.1007/s11524-015-9986-8.

[50] Mota, N. P., Medved, M., Wang, J., Asmundson, G. J. G., Whitney, D., \& Sareen, J.: Stress and mental disorders in female military personnel: Comparisons between the sexes in a male-dominated profession. 2012; J. Psychiatr. Res. 46 (2): 159-167. https://doi.org/10.1016/j.jpsychires.2011.09.014.

[51] Svedberg, P., Bildt, C., Lindelöw, M., \& Alexandersson, K.: Selfreported health among employees in relation to sex segregation at work sites. 2009; J. Occup. Health. 51 (3), 223-231.

[52] Milner A, King T, LaMontagne AD, Bentley R, \& Kavanagh A. Men's work, Women's work, and mental health: A longitudinal investigation of the relationship between the gender composition of occupations and mental health. 2018; Soc Sci Med.; 204: 16-22. https://doi.org/10.1016/j.socscimed.2018.03.020.

[53] Sawyer, P. J., Major, B., Casad, B. J., Townsend, S. S. M., \& Mendes, W. B. Discrimination and the stress response: Psychological and physiological consequences of anticipating prejudice in interethnic interactions. 2012; American Journal of Public Health, 102 (5), 1020-1026. https://doi.org /pdf/10.2105/AJPH.2011.300620.

[54] Brown, T. T., Partanen, J., Chuong, L., Villaverde, V., Griffin, A. C., \& Mendelson, A., Discrimination hurts the effect of discrimination on the development of chronic pain. 2018; Soc. Sci. Med. 204, 1-8.

[55] Kaiser CR, Vick SB, \& Major B. Prejudice expectations moderate preconscious attention to social identity threatening cues. 2006; Psychol Sci.; 17 (4): 332---338.

[56] [Pascoe EA, Smart Richmond L. Perceived discrimination and health: a meta-analytic review. Psychol Bull. 2009; 135 (4): $531---554$.

[57] Scrinzi, F. 2010 "Masculinities and the International Division of Care: Migrant Male Domestic Workers in Italy and France," Men and Masculinities, 13 (1), pp. 44-64. Sector', National Institute Economic Review 2006; 195, 103, Sage: London https://doi.org/10.1177/1097184X10382880. 
[58] Inzlicht, M., and Kang, S. K. Stereotype threat spillover: how coping with threats to social identity affects aggression, eating, decision making, and attention. 2010; J. Pers. Soc. Psychol. 99, 467-481. https://doi.org/10.1037/a0018951.

[59] Inzlicht, M., Tullett, A. M., Legault, L., \& Kang, S. K. Lingering effects: stereotype threat hurts more than you think. 2011; Soc. Issues Policy Rev. 5, 227-256. https://doi.org/10.1111/j.1751-2409.2011.01031.x.

[60] von Hippel, C., Sekaquaptewa, D., \& McFarlane, M. Stereotype threat among women in finance: negative effects on identity, workplace well-being, and recruiting. 2015; Psychol. Women Q. 39, 405-414. https://doi.org/10.1177/0361684315574501

[61] Smith, R. A. Money, benefits, and power: a test of the glass ceiling and glass escalator hypotheses. 2012; Ann. Am. Acad. Pol. Soc. Sci. 639, 149-172. https://doi.org/10.1177/0002716211422038.

[62] Woodhams, C., Lupton, B., \& Cowling, M. The presence of ethnic minority and disabled men in feminised work: intersectionality, vertical segregation, and the glass escalator. 2015; Sex Roles 72, 277-293. https://doi.org/10.1007/s11199. 014-0427-z.

[63] Park, R., \& Searcy, D. Job autonomy as a predictor of mental well-being: the moderating role of quality-competitive environment. 2012; J. Bus. Psychol. 27, 305-316. https://doi.org/0.1007/s10869-011-9244-3.

[64] Taylor, J., \& Westover, J. H. Job satisfaction in the public service: The effects of public service motivation, workplace attributes, and work relations. 2011; Public Management Review, 13, 731-751.

[65] Graves, L. M., \& Luciano, M. M. Self-determination at work: Understanding the role of leader-member exchange. 2012; Motivation and Emotion, 37, 518-536.

[66] Hassan, S. Sources of professional employees' job involvement: An empirical assessment in a government agency. 2014; Review of Public Personnel Administration, 34, 356-378.

[67] Baumeister, R. F., \& Alghamdi, N. Resource-based interventions in the workplace: integration, commentary, and recommendations. 2015; J. Occup. Organ. Psychol. 88, 623629. https://doi.org/10.1111/joop.12130.

[68] van Wingerden, J., \& Poell, R. F. Employees' perceived opportunities to craft and in-role performance: the mediating role of job crafting and work engagement. 2017; Front. Psychol. 8: 1876. https://doi.org/10.3389/fpsyg.2017. 01876. 